\title{
Anticoagulation for stroke prevention in elderly patients with non-valvular atrial fibrillation: what are the obstacles?
}

\author{
CW Wong *
}

\section{A B S T R A C T}

The elderly with atrial fibrillation are more prone to stroke. Oral anticoagulants such as warfarin are effective in the prevention of atrial fibrillationassociated stroke and systemic embolism. The $\mathrm{CHADS}_{2}$ or $\mathrm{CHA}_{2} \mathrm{DS}_{2}$-VASc score and HAS-BLED score were developed to stratify stroke risk associated with atrial fibrillation and bleeding risk in a patient with atrial fibrillation, respectively, to facilitate the decision for and safe use of oral anticoagulant. Nonetheless, the decision for anticoagulation is not straightforward and the elderly with nonvalvular atrial fibrillation are often precluded from anticoagulant prescription. Advanced age and disadvantages associated with the elderly such as fall, comorbidities, cognitive impairment, and polypharmacy contribute to the over-concern of physicians about bleeding risk. Various treatment options such as low-intensity warfarin and aspirin plus clopidogrel have been suggested but are inferior to dose-adjusted warfarin. Novel oral anticoagulants with promising efficacy and convenience hold great appeal. Optimal management of underlying medical conditions and modifiable stroke risk factors, together with intervention to improve the safe use of oral anticoagulants, are useful.
Hong Kong Med J 2016;22:608-15
DOI: $10.12809 / \mathrm{hkmj} 154803$
CW Wong * FHKCP, FHKAM (Medicine)
Department of Medicine and Geriatrics, Caritas Medical Centre,
Shamshuipo, Hong Kong
* Corresponding author: chitwaiwong@hotmail.com

\section{Introduction}

Atrial fibrillation (AF) is common in the elderly. The prevalence tends to increase with age with $1.7 \%$ in people aged $60-64$ years increasing to $17.8 \%$ in those aged $\geq 85$ years. ${ }^{1}$ A similar trend has been reported in the Chinese population despite a lower prevalence of $1.3 \%$ in the $60-69$ years' age-group and $7.5 \%$ in those aged $80-89$ years. $^{2}$

Atrial fibrillation is an independent risk factor for stroke. ${ }^{3}$ There is an almost five-fold increase in age-adjusted incidence of AF-associated stroke if no anticoagulation therapy is given. The attributable risk of stroke associated with other cardiovascular risk factors-such as hypertension, congestive heart failure, and ischaemic heart disease-decreases with age. In contrast, the attributable risk for stroke associated with AF increases with age, rising from $1.5 \%$ in people aged $50-59$ years to $23.5 \%$ in those aged 80-89 years. In addition, consequent stroke tends to be more severe with significant disability, and mortality rate is double that of non-AF stroke, especially in people $\geq 75$ years. ${ }^{4}$ Thus, older patients with AF are particularly prone to stroke and its adverse effects.

Antithrombotic therapy is effective in reducing AF stroke risk with oral anticoagulant (OAC) more efficacious than antiplatelet agents. ${ }^{5}$ Until recently and before the advent of novel OAC, the vitamin
$\mathrm{K}$ antagonist, warfarin, was the only OAC available and it is still the most common OAC prescribed nowadays. Nonetheless, warfarin is inconvenient to use and its associated bleeding risk is particularly troublesome for the elderly. As a consequence, it is often underutilised in the elderly.

\section{Stroke risk assessment}

Stroke risk varies widely in AF patients and depends on the presence of stroke risk factors. There are several risk stratification schemes to facilitate the decision to commence antithrombotic therapy of which the $\mathrm{CHADS}_{2}$ or $\mathrm{CHA}_{2} \mathrm{DS}_{2}$-VASc score is the most common and easy to use with satisfactory reliability (Table 1). ${ }^{6,7}$ The $\mathrm{CHA}_{2} \mathrm{DS}_{2}$-VASc score is an extension of the $\mathrm{CHADS}_{2}$ (congestive heart failure, hypertension, age $\geq 75$ years, diabetes mellitus, and prior stroke or transient ischaemic attack [TIA]) with the addition of other stroke risk factors (vascular disease in the form of prior myocardial infarction, plaque in aorta and peripheral artery disease, age 65-74 years, and female sex) that enable a more comprehensive stroke risk assessment. Prior stroke or TIA, and age $\geq 75$ years are regarded as major risk factors and score 2 points each while other risk factors are regarded as non-major risk factors and score 1 point each. Recommendation for antithrombotic therapy is based on the presence or 
absence of risk factors.

\section{Anticoagulant use in atrial fibrillation for stroke prevention}

An anticoagulant that clears clotting factors from the circulation to prevent blood clot formation is considered the most effective AF stroke preventive therapy. The traditional anticoagulant, the vitamin $\mathrm{K}$ antagonist-warfarin-impairs the synthesis of clotting factors II, VII, IX, and X; novel OACs selectively inhibit only thrombin (dabigatran) or factor Xa (rivaroxaban, apixaban, and edoxaban).

Adjusted-dose warfarin (target international normalised ratio [INR], 2-3) has been shown to reduce stroke risk by $64 \%$ while antiplatelet agents to reduce the risk by $22 \%{ }^{5}$; high-risk patients showed larger stroke risk reduction with warfarin. There was a small increase in major extracranial and intracranial haemorrhage $(\mathrm{ICH})$ risk $(0.2 \%-0.3 \%$ per year) associated with warfarin but overall mortality was significantly reduced (26\%) by warfarin.

The European Society of Cardiology incorporated the $\mathrm{CHADS}_{2} / \mathrm{CHA}_{2} \mathrm{DS}_{2}$-VASc risk stratification scheme into guidelines to help clinicians decide the most appropriate antithrombotic therapy. ${ }^{8}$ It recommends no treatment rather than aspirin for patients with $\mathrm{CHA}_{2} \mathrm{DS}_{2}$-VASc score of 0 (including female $<65$ years) because aspirin may not be better than no treatment in the reduction of stroke risk and increases the bleeding risk ${ }^{6}$; OAC is recommended for those who score $\geq 1$.

\section{Underutilisation of oral anticoagulant in the elderly}

The elderly with AF, especially those aged $\geq 75$ years, are considered to have at least one major risk factor

\section{為非瓣膜性心房顫動的老年患者處方預防中風的 抗凝血劑所遇到的難題 \\ 王哲慧}

心房顫動會增加老年人中風的風險。口服抗凝血劑如華法林是有效預 防心房顫動相關性中風及全身性栓塞的療法。醫生為病人處方口服抗 凝血劑時, 會使用CHADS 或CHA $2 \mathrm{DS}_{2}-\mathrm{VASc}$ 評分為心房顫動患者評 估中風的風險及使用HAS-BLED評分為患者評估出血的風險。然而, 為老年患者作出處方抗凝血劑的決定並不容易, 高齡和健康狀況不佳 的問題（如容易跌倒、長期病患、認知障礙和服用多種藥物等）往往 令醫生過度評估老年患者出血的風險。曾建議的其他治療方案包括低 劑量華法林和阿斯匹林加氯吡格雷, 但療效始終不及經調整劑量的華 法林。新型口服抗凝血劑是具吸引力的治療策略, 其療效可媲美華法 林以外, 使用上也更為方便和安全。治療及控制其他中風的高危因素 和其他病患, 並採取措施減低使用口服抗凝血劑的出血風險, 這都是 對患者有利的醫療方案。

for stroke with a $\mathrm{CHA}_{2} \mathrm{DS}_{2}-\mathrm{VASc}$ score of 2, thus, OAC is certainly recommended. Nonetheless, it is underutilised in the clinical setting. Among older patients with known AF without contra-indications to OAC and admitted for ischaemic stroke, only $40 \%$ were prescribed warfarin prior to the stroke event. ${ }^{9}$ Prescription rate decreased with increasing age, from $75 \%$ in those $<70$ years to $24 \%$ in those aged $\geq 90$ years. ${ }^{10}$

Overestimation of the bleeding risk and disadvantages associated with advanced age are barriers to prescription of OAC in the elderly. The most commonly cited reason not to anticoagulate is increased bleeding risk followed by fall risk. ${ }^{11}$

TABLE I. Stroke risk stratified by $\mathrm{CHA}_{2} \mathrm{DS}_{2}-\mathrm{VASc}$ score ${ }^{6,7}$

\begin{tabular}{|c|c|c|c|c|c|}
\hline \multicolumn{2}{|l|}{ CHADS $_{2}$} & \multicolumn{2}{|l|}{$\mathrm{CHA}_{2} \mathrm{DS}_{2}-\mathrm{VASc}$} & \multirow{2}{*}{$\begin{array}{c}\mathrm{CHA}_{2} \mathrm{DS}_{2}-\mathrm{VASc} \\
\text { score }\end{array}$} & \multirow{2}{*}{$\begin{array}{l}\text { Adjusted stroke } \\
\text { rate (\%/year) }\end{array}$} \\
\hline Risk factor & Score & Risk factor & Score & & \\
\hline $\mathrm{CHF}$ & 1 & CHF/LV dysfunction & 1 & 0 & 0 \\
\hline HT & 1 & HT & 1 & 1 & 1.3 \\
\hline Age $\geq 75$ years & 1 & Age $\geq 75$ years & 2 & 2 & 2.2 \\
\hline DM & 1 & DM & 1 & 3 & 3.2 \\
\hline \multirow[t]{5}{*}{ Prior stroke/TIA } & 2 & Stroke/TIA/TE & 2 & 4 & 4.0 \\
\hline & & Vascular disease (prior MI, PAD, or aortic plaque) & 1 & 5 & 6.7 \\
\hline & & Age $65-74$ years & 1 & 6 & 9.8 \\
\hline & & Sex (female) & 1 & 7 & 9.6 \\
\hline & & & & 8 & 6.7 \\
\hline Maximum score & 6 & Maximum score & 9 & 9 & 15.2 \\
\hline
\end{tabular}

Abbreviations: $\mathrm{CHF}=$ congestive heart failure; $\mathrm{DM}=$ diabetes mellitus; $\mathrm{HT}=$ hypertension; $\mathrm{LV}=$ left ventricle; $\mathrm{Ml}=$ myocardial infarction; $\mathrm{PAD}=$ peripheral arterial disease; $\mathrm{TE}=$ thromboembolism; $\mathrm{TI} \mathrm{A}=$ transient ischaemic attack 
Advanced age, co-morbidities, and patient compliance have also been reported to influence physician decision on anticoagulation. The inconvenience of frequent monitoring with dose adjustment, and drug and food interactions further contribute to OAC underuse. A small survey in Hong Kong showed that both physician awareness and patient knowledge of anticoagulation for AF stroke prevention is insufficient, which is another barrier to OAC use. ${ }^{12}$

\section{Advancing age}

The Birmingham Atrial Fibrillation Treatment of the Aged Study recruited nearly 1000 patients aged $\geq 75$ years with AF to receive either warfarin (INR, 2-3) or aspirin $75 \mathrm{mg}$ daily with a mean follow-up of 2.7 years. It revealed a significant reduction in ischaemic stroke in the warfarin group compared with the aspirin group (relative risk $=0.3 ; 95 \%$ confidence interval [CI], 0.13-0.63). ${ }^{13}$ The main benefit was seen in the reduction of severe or disabling non-fatal stroke. The efficacy of warfarin did not change with increasing age. There was no difference between the two groups in major bleeding rate.

Analysis of the Atrial Fibrillation Investigators database revealed that the relative benefit of OAC versus an antiplatelet agent and no antithrombotic therapy did not vary by age for ischaemic stroke prevention whilst the benefit of an antiplatelet agent decreased with age. ${ }^{14}$

Analysis of local registry data from 2339 non-valvular AF Chinese patients aged $\geq 80$ years demonstrated a lower rate of ischaemic stroke and death in patients prescribed warfarin (hazard ratio $=0.53$; 95\% CI, 0.48-0.58) but a higher $\mathrm{ICH}$ rate than in those without anti-thrombotic therapy after 2.2 years' follow-up ( $1.1 \%$ per year vs $0.6 \%$ per year). ${ }^{15}$ Overall, net clinical benefits favoured warfarin for all elderly patients, particularly those at high stroke and ICH risk.

Therefore, age alone should not be a reason to exclude anticoagulation.

\section{Bleeding}

Elderly patients are prone to anticoagulant-associated bleeding. The incidence of life-threatening or fatal bleeding has been shown to be significantly higher in elderly patients aged $\geq 80$ years than in those aged $<50$ years (relative risk $=4.6$; $95 \%$ CI, $1.2-18.1$ ) on warfarin. ${ }^{16}$ Major bleeding risk has been shown to rise with increasing age in AF patients regardless of anticoagulant use; patients $\geq 80$ years on warfarin were at particularly high risk of ICH. ${ }^{17}$ Further, ICH as a consequence of warfarin intake was associated with poor outcome; 3 -month mortality was double that of patients not taking warfarin..$^{18}$ The Chinese population has a higher background haemorrhagic stroke rate that accounts for at least $30 \%$ of all strokes. ${ }^{19}$ Together with a four-fold higher warfarin- associated $\mathrm{ICH}$ risk in Asians compared with whites,$^{20}$ concern about warfarin is even greater in Chinese elderly patients.

A simple bleeding risk score, HAS-BLED (hypertension, abnormal renal/liver disease, stroke history, bleeding history, liable INR, elderly $>65$ years, drugs/alcohol) [Table 2], has been derived to predict major bleeding risk in $\mathrm{AF}$ patients ${ }^{21}$ and incorporated into AF management guidelines as an indicator for bleeding risk. ${ }^{8}$ A score of $0-1$ indicates 'low risk' with annual bleeding rate of $<2 \%$, a score of 2-3 indicates 'moderate risk' with annual bleeding rate of $2 \%-4 \%$, and a score of $\geq 4$ indicates 'high risk' with annual bleeding rate of $>4 \%$. It is particularly useful in predicting major bleeding risk in patients who are receiving an antiplatelet agent alone or no antithrombotic therapy prior to the initiation of OAC. Its use is not to exclude patients from OAC but to identify modifiable bleeding risk factors that can then be corrected to minimise bleeding risk. Assessment of both $\mathrm{CHA}_{2} \mathrm{DS}_{2}$-VASc and HASBLED can help balance the stroke risk and bleeding risk in AF patients, but details of how to incorporate the $\mathrm{CHA}_{2} \mathrm{DS}_{2}$-VASc score into the HAS-BLED score to guide the management of AF needs further study.

TABLE 2. Clinical characteristics of the HAS-BLED bleeding risk score ${ }^{21}$

\begin{tabular}{lc}
\hline HAS-BLED & Score \\
\hline Hypertension* & 1 \\
\hline Abnormal renal and liver function (1 point each)† & 1 or 2 \\
\hline Stroke history & 1 \\
Bleeding $\ddagger$ & 1 \\
Labile international normalised ratios $\S$ & 1 \\
Elderly (>65 years) & 1 \\
Drugs or alcohol (1 point each)\| & 1 or 2 \\
Maximum score & $\mathbf{9}$ \\
\hline
\end{tabular}

* 'Hypertension' is defined as systolic blood pressure of $>160 \mathrm{~mm} \mathrm{Hg}$

+ 'Abnormal renal function' is defined as the presence of chronic dialysis or renal transplantation or serum creatinine of $\geq 200 \mu \mathrm{mol} / \mathrm{L}$. 'Abnormal liver function' is defined as chronic hepatic disease (eg cirrhosis) or biochemical evidence of significant hepatic derangement (eg bilirubin $>2 \times$ upper limit of normal, associated with aspartate transaminase/alanine transaminase/alkaline phosphatase $>3 \times$ upper limit normal)

$\ddagger$ 'Bleeding' refers to bleeding history or predisposition to bleeding (eg bleeding diathesis, anaemia)

$\S$ 'Labile international normalised ratios' refers to unstable/high international normalised ratios or poor time in therapeutic range (eg <60\%)

II Drugs/alcohol use refers to concomitant use of drugs, such as antiplatelet agents and non-steroidal anti-inflammatory drugs, or alcohol abuse 


\section{Fall}

Fall risk and fall-related head injury with $\mathrm{ICH}$ increase with age, which is another concern when considering anticoagulation.

Using pooled data from major AF trials, warfarin showed a net benefit of stroke protection in elderly patients with average stroke and fall risk over aspirin or no treatment in terms of higher qualityadjusted life-years. ${ }^{22}$ Regardless of patient age or baseline stroke risk, fall risk was not an important factor in determining optimal therapy: patients with average fall risk would need to fall 295 times in a year for warfarin not to be the optimal therapy.

Another database study of nearly 20000 elderly AF patients (mean age, 80 years) found that patients at high fall and stroke $\left(\mathrm{CHADS}_{2}\right.$ score $\left.\geq 2\right)$ risk appeared to have a net benefit from OAC despite an increased baseline ICH risk, in which OAC use was associated with a $25 \%$ relative risk reduction in the composite outcome of stroke, any haemorrhage, myocardial infarction and death whilst there was an insignificant reduction in those at high risk for fall but with $\mathrm{CHADS}_{2}$ score of 0 or $1 .^{23}$

A subsequent prospective study showed that among 515 AF patients discharged on OAC, there was no significant increase in major bleeding rate (including fatal haemorrhage and $\mathrm{ICH}$ ) in patients at high fall risk compared with those at low fall risk at 12 months. ${ }^{24}$

These data suggest that in patients with valid indications for anticoagulation, the benefits outweigh the risk, and fall risk should not be a sole reason to withhold anticoagulation.

\section{Narrow therapeutic range, co-morbidities, and polypharmacy}

Maintaining INR at 2 to 3 for at least $60 \%$ of the time provides effective stroke prevention and minimises bleeding risk. ${ }^{8}$ Nonetheless, maintaining this optimal range is not easy as it is influenced by both internal and external factors.

Consistent dietary intake of vitamin $\mathrm{K}$ is important for stable anticoagulation. This is difficult for elderly patients with poor health, who get sick frequently, have a poor diet and fluctuating vitamin $\mathrm{K}$ intake, or for patients with cognitive impairment who cannot comply with a diet with constant vitamin K content.

Many concurrent diseases can also influence INR control. It is particularly troublesome during the exacerbation of disease or if the disease course is fluctuating. Hepatic dysfunction impairs synthesis of clotting factors and thus potentiates the anticoagulation effects. Hepatic congestion as a result of congestive heart failure can inhibit warfarin metabolism and lead to accumulation of warfarin and over-anticoagulation. Hypermetabolic states such as febrile illness or thyrotoxicosis may increase catabolism of vitamin $\mathrm{K}$-dependent clotting factors and may increase INR level. ${ }^{25}$ On the contrary, hypothyroidism that decreases the catabolism of vitamin $\mathrm{K}$-dependent clotting factors may decrease INR. Patients with AF with concomitant acute coronary disease and percutaneous coronary intervention require aspirin-clopidogrel dual therapy in addition to warfarin, and this further increases bleeding risk. Patients with severe chronic kidney disease (estimated glomerular filtration rate, $<30 \mathrm{~mL} / \mathrm{min} / 1.73 \mathrm{~kg} / \mathrm{m}^{2}$ ) who are prescribed warfarin are at higher risk of over-anticoagulation, which is associated with more than double the risk for major bleeding compared with patients with mild or moderate chronic kidney disease. ${ }^{26}$ Patients with cognitive impairment have difficulty in managing their warfarin intake, coping with dosage adjustment, and being aware of drug and food interactions; all of which may result in over- or under-anticoagulation.

Warfarin can interact with many drugs and herbal products. This has clinical implications because polypharmacy and adjustment of medications due to an acute illness is frequent in the elderly. Polypharmacy is an independent risk factor for warfarin-related major bleeding and there is a $12 \%$ increase in risk for each additional drug taken. ${ }^{24}$ It is relatively easier to manage drugs in chronic use than those prescribed for a short period of time or when necessary. Warfarin-drug interaction is through the influence of pharmacokinetics that reduce gastrointestinal absorption or disrupts metabolic clearance and pharmacodynamics that alter the haemostatic response. ${ }^{25}$ The Box lists the common drugs and food that interact with warfarin. ${ }^{27}$ It should be noted that the majority of the data are from case series or reports because of the scarcity of randomised controlled trials. Thus, the rate of harm and its generalisation to all warfarin users needs continuous review. Nonetheless, physicians should proceed with caution and frequently monitor INR when prescribing potential offending drugs. There is a group of drugs that potentiate bleeding on their own without alteration of INR that includes antiplatelet drugs, heparin, non-steroidal antiinflammatory drugs (NSAIDs), cyclooxygenase-2 (COX-2) inhibitors, and selective serotonin reuptake inhibitors.

Pain syndrome and analgesic use are common in the elderly. Among analgesics, paracetamol is preferred for occasional use when taking warfarin. ${ }^{28}$ A dose that exceeds $2 \mathrm{~g}$ daily for more than a few days may raise INR and increase the bleeding risk, however. The NSAIDs, including COX-2 selective NSAIDs, should be avoided. Non-pharmacological methods of pain relief to minimise the use of analgesics are encouraged. 
BOX. Common drug and food interactions with warfarin ${ }^{27}$

Drugs/food with highly probable* potentiating effect on warfarin

- Cardiovascular drugs: amiodarone, propranolol, diltiazem

- Anti-infectives: cotrimoxazole, metronidazole, miconazole, fluconazole, ciprofloxacin, erythromycin, and isoniazid

- Gastrointestinal drugs: omeprazole, cimetidine

- Others: alcohol (if concomitant liver disease is present), mango, fish oil

Drugs/food with probable† potentiating effect on warfarin

- Anti-infectives: amoxicillin/clavulanate, azithromycin, clarithromycin, levofloxacin

- Analgesic/anti-inflammatories: paracetamol, tramadol, acetylsalicylic acid, celecoxib

- Others: simvastatin, tamoxifen, grapefruit, denshen, dong quai

Drugs/food with highly probable* inhibiting effect on warfarin

- Central nervous system drugs: barbiturate, carbamazepine

- Antibiotics/antifungals: rifampicin, griseofulvin

- Others: cholestyramine, high vitamin content foods/enteral feeds

Drugs/food with no interaction with warfarin

- Antacid, atenolol, famotidine, felodipine, fluoxetine, metoprolol, naproxen, ibuprofen

Phenytoin

- Either increase or decrease the effect of warfarin as it can induce both warfarin and clotting factors metabolism and displace warfarin from its protein-binding sites

* Highly probable requires causative criteria $A, B, C$, and $\geq 1$ of $D$ to $G$ (see below)

† Probable requires causative criteria $A, B$, and $\geq 1$ of $C$ to $G$ (see below)

A. Timing was correct for an interaction to be pharmacologically plausible

B. Laboratory test (eg international normalised ratio) supported the interaction

C. Other potential factors affecting warfarin pharmacokinetic/pharmacodynamic were ruled out

D. Patient had a similar result with previous exposure to the same drug

E. Dose-response relationship was demonstrated for the interacting drugs

F. Similar response occurred or rechallenged

G. Authors' conclusion from the studies supported by other objective evidence

\section{Undiagnosed/occult atrial fibrillation}

It is not uncommon for a patient to have AF first diagnosed when ischaemic stroke occurs. Very often, $\mathrm{AF}$ is undiagnosed as it is usually asymptomatic; $10 \%$ to $40 \%$ of $\mathrm{AF}$ cases are asymptomatic..$^{29} \mathrm{~A}$ population-based study revealed that $20.1 \%$ of $\mathrm{AF}$ in patients aged $>60$ years was undiagnosed. ${ }^{30}$ Paroxysmal AF, which bears a similar stroke risk and benefit from anticoagulation to sustained $\mathrm{AF}^{31}$ also easily evades ordinary electrocardiography (ECG) screening. Paroxysmal AF is common (up to $16 \%$ ) in cryptogenic stroke ${ }^{32}$ that constitutes $25 \%$ of ischaemic stroke. ${ }^{33}$

\section{Alternatives to warfarin}

\section{Low-intensity warfarin}

Intensity of anticoagulation correlates directly with incidence of haemorrhage, ${ }^{34}$ thus low-intensity warfarin with a subtherapeutic range of INR, such as INR of $<2$, is suggested for the elderly to lower bleeding risk while still effectively preventing stroke. The Boston Area Anticoagulation Trial for Atrial Fibrillation Investigators found that low-dose warfarin (target INR, 1.5-2.7) was more effective than placebo in stroke prevention. ${ }^{35}$ There is a racial difference in response to warfarin-a lower INR target of 1.8 to 2.4 appears to be sufficient in lowering both major bleeding and thromboembolic events in Chinese. ${ }^{36}$ Japanese studies and their registry data also support the lower INR target and have recommended INR of 1.6 to 2.6 for AF patients of $\geq 70$ years in their AF management guideline. ${ }^{37}$

\section{Aspirin plus clopidogrel}

Aspirin (75-100 mg daily)-clopidogrel (75 mg daily) dual therapy has been shown to be better than aspirin alone in stroke prevention in AF patients, reducing stroke risk by $28 \%$ compared with aspirin alone. ${ }^{38}$ Nonetheless, it is inferior to OAC in AF patients with at least one risk factor for stroke; OAC reduced stroke risk by $42 \%$ compared with dual therapy. ${ }^{39}$ Both dual therapy and OAC were associated with similar but higher bleeding risk than aspirin. Therefore, dual therapy may only be considered for patients in whom OAC is unsuitable or for patient preference. ${ }^{8}$

\section{Novel oral anticoagulants}

Novel OACs (dabigatran, rivaroxaban, apixaban, and edoxaban) have been approved by the US Food and Drug Administration (FDA) for AF stroke prevention. They have undergone large clinical trials in AF patients (mean age $\geq 70$ years) with at least one additional stroke risk factor. Rivaroxaban, dabigatran $110 \mathrm{mg}$, and edoxaban were non-inferior whilst both apixaban and dabigatran $150 \mathrm{mg}$ were superior to warfarin in stroke or systemic embolism 
prevention; overall they significantly reduced the risk by $19 \%$ compared with warfarin, mainly due to a large reduction in haemorrhagic stroke..$^{40}$ All-cause mortality was also significantly reduced by $10 \%$. The newer anticoagulants appear to be safer with at least a similar major bleeding rate and consistently lower $\mathrm{ICH}$ rate $(>50 \%$ fewer) compared with warfarin. The exception is gastrointestinal bleeding risk in dabigatran $150 \mathrm{mg}$, rivaroxaban and edoxaban 60 $\mathrm{mg}$, occurrence of which was $25 \%$ more than with warfarin. The favourable result was sustained across a wide stratum of patients at high risk of both ischaemic and bleeding events. The efficacy and safety of novel OACs are consistent among Asian patients including Chinese ${ }^{41-43}$ as well as Chinese elderly aged $\geq 80$ years. ${ }^{44}$ Because of the favourable efficacy and safety profile, current guidelines have recommended novel OACs as an alternative to warfarin in primary and secondary stroke prevention in patients with non-valvular AF. ${ }^{8}$

In addition, novel OACs are convenient because of their predictable and reliable anticoagulation properties, with far fewer drug interactions and no food interactions or dietary restrictions. They can be administered at a fixed dose and monitoring of coagulation is unnecessary.

Nonetheless, their use is not without drawbacks. They are eliminated renally, thus dose adjustment based on renal function is required and they are not recommended for patients with severely impaired renal function (creatinine-clearance, $<15$ $\mathrm{mL} / \mathrm{min}$ ). Although drug interactions are fewer than those for warfarin, there is potential interaction with P-glycoprotein and CY3A4 inhibitors or inducers, which include common cardiovascular drugs such as amiodarone, dronedarone and diltiazem (all are combined P-glycoprotein inhibitors and weak/ moderate CYP3A4 inhibitors), and anti-infectives such as rifampicin (strong CYP3A4 inducers), clarithromycin and ketoconazole (strong dual inhibitors of P-glycoprotein and CYP3A4), thus caution is required. Because they do not affect INR and there is no readily available measure to monitor their anticoagulation, it is difficult to confirm if patients are compliant with therapy. Thus, good drug compliance is as important as taking warfarin. Besides, the cost of novel OAC is more expensive and long-term evidence is not complete. For those patients already on warfarin who have satisfactory anticoagulation control, whether there is extra benefit in switching to novel OAC needs to be explored.

\section{Left atrial appendage closure}

Since $>90 \%$ non-valvular AF stroke inducing thromboemboli are from the left atrial appendage (LAA), LAA closure is considered an alternative to OAC.45 Percutaneous occlusion by placing the WATCHMAN device in the LAA was approved by the US FDA for the prevention of LAA thromboembolism in patients in whom OAC was contra-indicated or in whom management with an OAC was difficult. The WATCHMAN device was shown to be noninferior to OAC in the composite endpoint of stroke, cardiovascular death, and systemic embolism. ${ }^{46}$ Main adverse effects are procedure-related, eg pericardial effusion, incomplete LAA closure, dislodgement of device, and blood clot formation on the device that requires prolonged OAC.

\section{Decision-making and strategies to improve}

The aim of prescribing OAC to AF patients is to prevent stroke or systemic embolism such that patients' health and functional state can be maintained. The decision to prescribe an OAC in the elderly is complicated, however. It requires not only balancing the stroke risk and bleeding risk from OAC, but also needs to consider the patient's general health, functional and cognitive ability, availability of a caregiver, and patient's attitude and preference towards anticoagulation. Elderly patients with AF who are in good health or have few co-morbidities and a good functional state will definitely benefit from OAC; for patients in poor health with multiple co-morbidities who are functionally dependent, OAC is not likely to provide additional benefit and there is a high risk of bleeding. Apart from that, decision making for other clinical scenarios is not easy. Careful assessment and discussion with patients and/or caregivers is essential when deciding whether to prescribe OAC.

Better preparation of eligible patients for anticoagulation by optimising their medical condition to reduce the risk of stroke and bleeding, together with education of patients and caregiver to enhance compliance, are also useful. The following are recommendations to improve the safety and optimal effect of OAC:

- Co-morbidities: optimise underlying medical conditions, increase frequency of anticoagulation monitoring if medical condition changes or during acute illness

- Cardiovascular risk factors: screening for and proper control of modifiable cardiovascular risk factors

- Cognitive impairment: encourage involvement of caregiver to ensure compliance

- Polypharmacy: review and simplify drug regimen; discontinue unnecessary medications, avoid drugs that interact with OAC or use alternative drugs with less potential for interaction; frequent INR monitoring if offending drugs are prescribed or discontinued

- Bleeding: avoid concomitant medications associated with bleeding such as antiplatelet 
agent, NSAIDs and alcohol; better control of hypertension to lower $\mathrm{ICH}$ risk $^{47}$; add proton pump inhibitor to lower upper gastrointestinal bleeding risk, especially those at increased risk ${ }^{48}$

- Fall prevention: fall risk assessment followed by intervention such as exercises for gait, balance, and strength training; education to increase safety awareness, prescription of appropriate walking aids, correction of vision if necessary, environmental modifications, and minimise or avoid offending medications

- Undiagnosed AF: liberal recording of ECGs in the elderly, especially those with cardiovascular risk factors, to capture $\mathrm{AF}^{49}$; for those with cryptogenic stroke, vigorously look for occult AF by prolonged ECG monitoring ${ }^{32}$

- Regular assessment of patient compliance with $\mathrm{OAC}$, and review of stroke and bleeding risk and adjust the management plan accordingly

- Continued education for physicians about AF and OAC management

- Setting up of a warfarin clinic in Hong Kong with a multidisciplinary approach (physicians, pharmacists, and nurses) to provide patient education, regular INR monitoring with warfarin dosage adjustment, monitoring of drug and food interactions, and signs of bleeding have been shown to improve drug compliance, minimise bleeding risk, and maintain INR within the therapeutic range ${ }^{50}$

\section{Conclusion}

The elderly with AF are more prone to stroke than younger patients, especially those aged $\geq 75$ years. Anticoagulation is effective in the prevention of stroke in the elderly despite the increased bleeding risk. Age alone should not exclude anticoagulation. Novel OAC is convenient with comparable efficacy to warfarin and a lower risk for $\mathrm{ICH}$. This may improve the prescription, however, long-term evidence is awaited. The best management of the elderly with AF depends on careful estimation of thromboembolic and bleeding risk, patient's ability to cope with anticoagulation, and patient preference. Optimal control of other potential risk factors for stroke and bleeding is also important.

\section{References}

1. Heeringa J, van der Kuip DA, Hofman A, et al. Prevalence, incidence and lifetime risk of atrial fibrillation: the Rotterdam study. Eur Heart J 2006;27:949-53.

2. Zhou Z, Hu D. An epidemiological study on the prevalence of atrial fibrillation in the Chinese population of mainland China. J Epidemiol 2008;18:209-16.

3. Wolf PA, Abbott RD, Kannel WB. Atrial fibrillation as an independent risk factor for stroke: the Framingham Study. Stroke 1991;22:983-8.

4. Lin HJ, Wolf PA, Kelly-Hayes M, et al. Stroke severity in atrial fibrillation. The Framingham Study. Stroke
1996;27:1760-4

5. Hart RG, Pearce LA, Aguilar MI. Meta-analysis: antithrombotic therapy to prevent stroke in patients who have nonvalvular atrial fibrillation. Ann Intern Med 2007;146:857-67.

6. Gage BF, Waterman AD, Shannon W, Boechler M, Rich MW, Radford MJ. Validation of clinical classification schemes for predicting stroke: results from the National Registry of Atrial Fibrillation. JAMA 2001;285:2864-70.

7. Lip GY, Nieuwlaat R, Pisters R, Lane DA, Crijns HJ. Refining clinical risk stratification for predicting stroke and thromboembolism in atrial fibrillation using a novel risk factor-based approach: the Euro Heart Survey on atrial fibrillation. Chest 2010;137:263-72.

8. Camm AJ, Lip GY, De Caterina R, et al. 2012 Focused update of the ESC Guidelines for the management of atrial fibrillation: an update of the 2010 ESC Guidelines for the management of atrial fibrillation. Developed with the special contribution of the European Heart Rhythm Association. Eur Heart J 2012;33:2719-47.

9. Gladstone DJ, Bui E, Fang J, et al. Potentially preventable strokes in high-risk patients with atrial fibrillation who are not adequately anticoagulated. Stroke 2009;40:235-40.

10. Hylek EM, D’Antonio J, Evans-Molina C, Shea C, Henault LE, Regan S. Translating the results of randomized trials into clinical practice: the challenge of warfarin candidacy among hospitalized elderly patients with atrial fibrillation. Stroke 2006;37:1075-80.

11. Pugh D, Pugh J, Mead GE. Attitudes of physicians regarding anticoagulation for atrial fibrillation: a systematic review. Age Ageing 2011;40:675-83.

12. Lee VW, Tam CS, Yan BP, Yu CM, Lam YY. Barriers to warfarin use for stroke prevention in patients with atrial fibrillation in Hong Kong. Clin Cardiol 2013;36:166-71.

13. Mant J, Hobbs FD, Fletcher K, et al. Warfarin versus aspirin for stroke prevention in an elderly community population with atrial fibrillation (the Birmingham Atrial Fibrillation Treatment of the Aged Study, BAFTA): a randomised controlled trial. Lancet 2007;370:493-503.

14. van Walraven C, Hart RG, Connolly S, et al. Effect of age on stroke prevention therapy in patients with atrial fibrillation: the Atrial Fibrillation Investigators. Stroke 2009;40:14106.

15. Siu CW, Tse HF. Net clinical benefit of warfarin therapy in elderly Chinese patients with atrial fibrillation. Circ Arrhythm Electrophysiol 2014;7:300-6.

16. Fihn SD, Callahan CM, Martin DC, McDonell MB, Henikoff JG, White RH. The risk for and severity of bleeding complications in elderly patients treated with warfarin. The National Consortium of Anticoagulation Clinics. Ann Intern Med 1996;124:970-9.

17. Fang MC, Go AS, Hylek EM, et al. Age and the risk of warfarin-associated hemorrhage: the anticoagulation and risk factors in atrial fibrillation study. J Am Geriatr Soc 2006;54:1231-6.

18. Rosand J, Eckman MH, Knudsen KA, Singer DE, Greenberg SM. The effect of warfarin and intensity of anticoagulation on outcome of intracerebral hemorrhage. Arch Intern Med 2004;164:880-4.

19. Zhang LF, Yang J, Hong Z, et al. Proportion of different subtypes of stroke in China. Stroke 2003;34:2091-6.

20. Shen AY, Yao JF, Brar SS, Jorgensen MB, Chen W. Racial/ ethnic differences in the risk of intracranial hemorrhage among patients with atrial fibrillation. J Am Coll Cardiol 
2007;50:309-15.

21. Pisters R, Lane DA, Nieuwlaat R, de Vos CB, Crijns HJ, Lip GY. A novel user-friendly score (HAS-BLED) to assess 1-year risk of major bleeding in patients with atrial fibrillation: the Euro Heart Survey. Chest 2010;138:1093100.

22. Man-Son-Hing M, Nichol G, Lau A, Laupacis A. Choosing antithrombotic therapy for elderly patients with atrial fibrillation who are at risk for falls. Arch Intern Med 1999;159:677-85.

23. Gage BF, Birman-Deych E, Kerzner R, Radford MJ, Nilasena DS, Rich MW. Incidence of intracranial hemorrhage in patients with atrial fibrillation who are prone to fall. Am J Med 2005;118:612-7.

24. Donzé J, Clair C, Hug B, et al. Risk of falls and major bleeds in patients on oral anticoagulation therapy. Am J Med 2012;125:773-8.

25. Hirsh J, Fuster V, Ansell J, Halperin JL; American Heart Association/American College of Cardiology Foundation. American Heart Association/American College of Cardiology Foundation guide to warfarin therapy. Circulation 2003;107:1692-711.

26. Limdi NA, Beasley TM, Baird MF, et al. Kidney function influences warfarin responsiveness and hemorrhagic complications. J Am Soc Nephrol 2009;20:912-21.

27. Holbrook AM, Pereira JA, Labiris R, et al. Systematic overview of warfarin and its drug and food interactions. Arch Intern Med 2005;165:1095-106.

28. NHS choices. Can I take paracetamol if I'm on warfarin? Available from: http://www.nhs.uk/chq/pages/858.aspx?ca tegoryid=73\&subcategoryid=103. Accessed Oct 2016.

29. Rho RW, Page RL. Asymptomatic atrial fibrillation. Prog Cardiovasc Dis 2005;48:79-87.

30. Clua-Espuny JL, Lechuga-Duran I, Bosch-Princep R, et al. Prevalence of undiagnosed atrial fibrillation and of that not being treated with anticoagulant drugs: the AFABE study. Rev Esp Cardiol (Engl Ed) 2013;66:545-52.

31. Hohnloser SH, Pajitnev D, Pogue J, et al. Incidence of stroke in paroxysmal versus sustained atrial fibrillation in patients taking oral anticoagulation or combined antiplatelet therapy: an ACTIVE W Substudy. J Am Coll Cardiol 2007;50:2156-61.

32. Gladstone DJ, Spring M, Dorian P, et al. Atrial fibrillation in patients with cryptogenic stroke. $\mathrm{N}$ Engl J Med 2014;370:2467-77.

33. Hart RG, Diener HC, Coutts SB, et al. Embolic strokes of undetermined source: the case for a new clinical construct. Lancet Neurol 2014;13:429-38.

34. Levine MN, Hirsh J, Landefeld S, Raskob G. Hemorrhagic complications of anticoagulant treatment. Chest 1992;102(4 Suppl):352S-363S.

35 . The effect of low-dose warfarin on the risk of stroke in patients with nonrheumatic atrial fibrillation. The Boston Area Anticoagulation Trial for Atrial Fibrillation Investigators. N Engl J Med 1990;323:1505-11.

36. You JH, Chan FW, Wong RS, Cheng G. Is INR between 2.0 and 3.0 the optimal level for Chinese patients on warfarin therapy for moderate-intensity anticoagulation? Br J Clin Pharmacol 2005;59:582-7.

37. JCS Joint Working Group. Guidelines for pharmacotherapy of atrial fibrillation (JCS 2008): digest version. Circ J 2010;74:2479-500.

38. ACTIVE Investigators, Connolly SJ, Pogue J, et al. Effect of clopidogrel added to aspirin in patients with atrial fibrillation. N Engl J Med 2009;360:2066-78.

39. ACTIVE Writing Group of the ACTIVE Investigators, Connolly S, Pogue J, et al. Clopidogrel plus aspirin versus oral anticoagulation for atrial fibrillation in the Atrial fibrillation Clopidogrel Trial with Irbesartan for prevention of Vascular Events (ACTIVE W): a randomised controlled trial. Lancet 2006;367:1903-12.

40. Ruff CT, Giugliano RP, Braunwald E, et al. Comparison of the efficacy and safety of new oral anticoagulants with warfarin in patients with atrial fibrillation: a meta-analysis of randomised trials. Lancet 2014;383:955-62.

41. Hori M, Connolly SJ, Zhu J, et al. Dabigatran versus warfarin: effects on ischemic and hemorrhagic strokes and bleeding in Asians and non-Asians with atrial fibrillation. Stroke 2013;44:1891-6.

42. Wong KS, Hu DY, Oomman A, et al. Rivaroxaban for stroke prevention in East Asian patients from the ROCKET AF Trial. Stroke 2014;45:1739-47.

43. Goto S, Zhu J, Liu L, et al. Efficacy and safety of apixaban compared with warfarin for stroke prevention in patients with atrial fibrillation from East Asia: a subanalysis of the Apixaban for Reduction in Stroke and Other Thromboembolic Events in Atrial Fibrillation (ARISTOTLE) Trial. Am Heart J 2014;168:303-9.

44. Chan PH, Huang D, Hai JJ, et al. Stroke prevention using dabigatran in elderly Chinese patients with atrial fibrillation. Heart Rhythm 2016;13:366-73.

45. Blackshear JL, Odell JA. Appendage obliteration to reduce stroke in cardiac surgical patients with atrial fibrillation. Ann Thorac Surg 1996;61:755-9.

46. Holmes DR, Reddy VY, Turi ZG, et al. Percutaneous closure of the left atrial appendage versus warfarin therapy for prevention of stroke in patients with atrial fibrillation: a randomised non-inferiority trial. Lancet 2009;374:53442.

47. Hart RG, Tonarelli SB, Pearce LA. Avoiding central nervous system bleeding during antithrombotic therapy: recent data and ideas. Stroke 2005;36:1588-93.

48. Lin KJ, Hernández-Díaz S, García Rodríguez LA. Acid suppressants reduce risk of gastrointestinal bleeding in patients on antithrombotic or anti-inflammatory therapy. Gastroenterology 2011;141:71-9.

49. Samol A, Masin M, Gellner R, et al. Prevalence of unknown atrial fibrillation in patients with risk factors. Europace 2013;15:657-62.

50. Outcome evaluation of warfarin clinic: safe and feasible care delivery model in primary care setting. Hong Kong Hospital Authority Convention 2008. Available from: http://www3. ha.org.hk/haconvention/hac2008/proceedings/pdf/ Free\%20Paper/SPP6-1.pdf. Accessed Oct 2016. 